\title{
Application status and development trend of blending teaching mode: application analysis based on MOOC, microlecture and flipped classroom
}

\author{
Zhao Hui, Zhang Dan \\ Xingzhi College of Xi'an University of Finance and Economics,Xi'an, Shaanxi,China \\ Xi'an University of Arts and Science,Xi'an, Shaanxi,China \\ 64050774@qq.com; 1493194624@qq.com
}

Corresponding author: Zhao Hui

Keywords: Blending teaching mode; Application status; MOOC; Microlecture;Flipped classroom

\begin{abstract}
In the 19th National Congress of CPC, Xi Jinping put forward the need to speed up the modernization of education and promote the reform of education. As a modern educational mode, blending teaching mode in colleges and universities has achieved gratifying results in promoting the construction of applied courses and the transformation of achievements which provides a broad idea and direction for the implementation of educational reform. The application development of blending teaching mode needs to be deepened constantly. Therefore, we explore the technological needs of basic means such as MOOC, microlecture and flipped classroom to strengthen the systematic construction of network course platform, constantly improve the quality control and feedback mechanism of blending teaching and gradually realize the systematic transformation from "teaching" to "learning".
\end{abstract}

\section{Introduction}

In the report to the 19th National Congress of the CPC, general secretary Xi Jinping called for giving priority to the development of education as a top priority in the cause of reform. He pointed out that we must speed up education reform and the modernization of education to run well the education to the satisfaction of the people. Blending teaching mode is put forward on the basis of absorbing from foreign excellent teaching achievements in order to meet the overall requirements of education reform. At present, teaching reform and course construction have been carried out extensively in colleges and universities in China. Blending teaching mode has been deeply developed which has the characteristics of inspiration and practicality and so on. Blending teaching mode improves the enthusiasm and initiative of students, deepens the understanding of teaching laws of university teachers and improves the overall quality of school personnel training.

\section{Connotation of blending teaching mode}

There is a difference between blending teaching mode and traditional education mode. Blending teaching mode is based on the perceptual experience of human beings, constructed with meaningful perceptual materials, and characterized by teaching concrete and open knowledge to make students experience meaning and stimulate their interest in learning. It is the mutual penetration of traditional learning methods and E-learning. It not only gives full play to the leading role of teachers in guiding, inspiring and managing classroom teaching, but also embodies the characteristics of taking students as the main body. Blending teaching mode is a highly efficient teaching mode. Yang Zhichao, a domestic scholar, thinks that the blending classroom can redefine the teaching function and content of the course to realize the complementary advantages of multiple teaching spaces [1]. Blended teaching usually has the following basic contents: (1) It takes the Internet as the basic teaching platform, online and offline teaching activities will be launched. (2) Blending teaching model has perfect design of teaching objectives, teaching process and teaching evaluation with a strict teaching feedback 
mechanism. (3) Blending teaching mode has no unified classroom standard which belongs to the problem-oriented classroom teaching mode.

Based on the reform of traditional teaching methods, blending teaching mode in domestic colleges and universities is often combining face-to-face teaching with network teaching to achieve complementary advantages[2]. Through the advanced teaching concepts and methods of MOOC, microlecture and flipped classroom at home and abroad, the extension of blending teaching mode is constantly expanded. Blending teaching mode in domestic universities is mostly carried out in this way. Blending teaching mode itself is dynamic. However, it should be emphasized that the application of blending teaching methods is the core and key of the blending teaching mode, while MOOC, microlecture and flipped classroom are only examples of blending teaching.

\section{The application status of blending teaching mode in MOOC, microlecture and flipped classroom in universities}

\subsection{The application status of college course reform and blending teaching mode}

University course reform is an important way to popularize blending teaching mode. The success of university course reform depends on the following three conditions: First of all, schools should set up projects and push them forward. Secondly, teachers should change their concepts and teaching roles to take students as the center. Thirdly, teachers' teaching methods and evaluation feedback methods should be changed. Most universities in China have issued the implementation plan of classroom teaching reform. For example, Inner Mongolia University for The Nationalities approved 33 courses in the first batch and carried out the reform of blending teaching mode. The school has a total of four batches and has conducted 261 courses. In addition, the school has approved the 192 online network resources construction course. In the teaching model design, a number of excellent ideas and results emerged. Li Fengqing, as a domestic scholar, has developed the teaching design model of ADDIE which divides teaching into three stages: pre-class, middle-class and after-class. On the basis of this theory, most colleges and teachers integrate the teaching modes of MOOC, microlecture and flipped classroom in course design. In particular, different teaching links are integrated according to the characteristics of different teaching methods such as MOOC, microlecture and flipped classroom.

The key word of MOOC is "customization". The whole teaching process of MOOC is completed through the network which needs to provide basic video materials, offline discussion courses and WeChat Subscription to learn according to students'needs. Therefore, blending learning in university is more evident. The main achievement and means of microlecture in colleges and universities is micro-video. However, the teaching of microlecture is interlaced with such teaching links as centralized exhibition, expert comments and sharing exchanges and even discussion on micro-blog platform. Microlecture has also become a typical example of blending teaching. Flipped classroom include the preparation stage for mastering the use of software tools, the pre-class learning stage with the help of network video or PPT display and the classroom discussion stage in which teachers and students answer open questions. Undoubtedly, the flipped classroom in universities is also an important example of blending teaching mode. Wei Shoulian, a Chinese scholar, designs university chemistry courses by using network images, animation and video [3]. Huazhong University of Science and Technology combines the advantages of traditional classroom with flipped classroom, and constructs a blending teaching mode of "self-study for video, animation and courseware before class, classroom teaching and interactive communication in the middle of class, and induction and summary after class ". Teachers help students build a comprehensive knowledge system in the classroom. Students learn resources autonomously before class, and absorb knowledge after class. Through the combination of classroom instruction and autonomous learning after class, the teaching and learning have been realized. Generally speaking, there are various and interrelated methods in the use of MOOC, microlecture and flipped classroom. Blending teaching mode itself is a fusion and application of a variety of teaching design. 


\subsection{Transformation of scientific research achievements in blending teaching mode in Universities}

Since 2001, blending teaching mode has become one of the hotspots in educational technology and training fields. From 2001 to 2017, the research papers of blending teaching mode showed an obvious growth trend by searching CNKI. Especially in the transformation of teaching courses and scientific research achievements, both in innovation and academic depth, have been significantly strengthened. Consistent with the situation of blending education and course reform in colleges and universities, the research objects of scientific papers are mostly focused on the comparison, contrast and exploration of different teaching methods such as MOOC, microlecture and flipped classroom. In addition to theoretical analysis, some papers provide a solid empirical basis for the application of blending teaching reform in colleges and universities with the help of detailed data. According to the region of the paper published and the region of the research object, the research workers of the paper are mostly concentrated in Mid-Eastern universities. This shows that the reform process is relatively fast in Mid-Eastern districts, and the reform results are relatively prominent. The most important reason is that the network technology is developed in Mid-Eastern districts, and the blending teaching reform itself needs to rely on certain Internet technology, Internet-related hardware manufacturing, and especially with the Collaboration of Industry-University-Research for modern information technology.

In addition to the transformation of research papers, universities in Mid-Eastern districts usually hold teaching activities such as teaching evaluation, flipped classroom or microlecture teaching competitions which promote the popularity of blending teaching mode in colleges and universities throughout the country in terms of achievements in scientific research application. Data analysis shows that more than $70 \%$ of the authors of papers on blending teaching mode come from universities which show that universities are the backbone power of the research on blending teaching mode. Among them, the support from special funds of the state and governments plays a very important role. According to the experience of microlecture production abroad, the extracurricular enterprises play a very important role in the course design and production. Multimedia project products, such as PPT, video production, can not be effectively completed without cooperation with extracurricular enterprises.

It can be said that blending teaching mode effectively combines Industry-University-Research Collaboration of universities and enterprises, and the application prospect of relevant scientific research results is more promising.

\section{The development trend of blending teaching mode in Universities}

\subsection{Starting from the technical needs of MOOC, microlecture and flipped classroom, we should strengthen systematic construction of network courses platform.}

With the development of the times and the progress of science and technology, if we want to keep pace with the times, we must constantly accept new things. Especially in education, we need to innovate and break the rules. Nowadays, more and more online teaching is becoming popular. Various educational platforms and institutions have offered online courses one after another. Through the combination of online and offline courses, students can receive education more easily. This combination can provide learners with more resources and independent learning opportunities. At the same time, China's education model is constantly innovating and trying to open new teaching models. Online course development is becoming more and more important. In a word, MOOC(large-scale online courses), microlecture and flipped classroom are all online course development models which need the systematic construction of the network course platform. Especially for large-scale online courses, such as MOOC, it is necessary to teach through the Internet course platform. Internet teaching is not limited by place, time and space which provides a model for large-scale course construction. We can carry out blending teaching better through network course teaching. Teachers teach students knowledge on multimedia computer networks which is more 
efficient and faster because they are not restricted by space. Besides, it can avoid students being influenced by external environment and students can concentrate on learning knowledge. Gao Jianhua, a domestic scholar, emphasizes that blending teaching model must be examined from the perspective of educational technology whose technical requirements are far higher than other online courses [4]. Therefore, we must strengthen the systematic construction of network course platform from the following aspects.

Do a good job in the construction and maintenance of network courses. A good platform will be more conducive to display and publicity. Maintaining network environment is the foundation of a good network course. Improve the special functions of network courses such as MOOC and microlecture, and provide multi-dimensional display, teaching evaluation and learning log modules of network courses. Improve the course structure, regularly maintain the network course, constantly revise and update the course content to ensure the advanced and scientific nature of the course. Teachers play a guiding role in network courses. Teachers not only teach knowledge to students, but also achieve the correct role of guiding learning. Exchange and guide with students, and properly solve the functional problems of network use by exchanging views and opinions with each other. Strengthen the management of network courses, make a scientific and reasonable teaching plan, correctly positioning the use of network courses to stimulate students'interest in learning and make full use of the network to provide high-quality network teaching.

\subsection{The quality monitoring and feedback mechanism of blending teaching classroom is constantly improving.}

According to the survey, $35 \%$ of the students were more willing to discuss the image \&text in class. It can be seen that learners prefer lively teaching methods and atmosphere. Blending teaching is a kind of "online" + "offline" teaching which combines the advantages of online teaching and traditional teaching. Despite its advantages and characteristics, it is more difficult to control the quality effect. Therefore, classroom quality monitoring must be a multi-level, multi-perspective detection and control system for blending teaching classroom. Classroom quality control must be able to effectively control and understand class quality and teaching effect.

There are several requirements for monitoring and feedback of classroom quality: Establish an effective classroom supervision system and communicating groups between teachers and learners which is essential to feedback timely on the shortcomings of the classroom in the communicating groups after class. Establish a scientific and systematic teaching and research group, hold regular teacher meetings, summarize classroom performance and form a written summary. Analyze the problems and discuss solutions in the meeting. Grasp the learner's .learning situation by assigning homework. A variety of assignments that are small but precise and are closely linked to learning topics and forms. It is necessary to establish a staged evaluation system for classroom teaching which combines the promotion bonus of teachers with course performance and classroom quality to fully arouse the enthusiasm of teachers.

\subsection{In general, we should gradually realize the transformation from "teaching" as the center to "learning" as the center.}

According to the examples of MOOC, microlecture and flipped classroom in colleges and universities, blending teaching mode usually has the following functions: It creates an environment for students to learn autonomously and lightens the teaching burden of teachers. It is easier to improve students'innovative consciousness and ability, and promote more communication and understanding between students and teachers. In order to better teach students in accordance with their aptitude and abilities, the self-confidence of underachievers should be established by means of stratified and staged teaching. 


\section{Summary}

Combining the actual effect and function of blending teaching mode, we must integrate "knowledge and skills, process and method, emotional attitude and values" to construct the teaching goal of the group teaching mode. It is necessary to strengthen the training of teachers'relevant teaching skills. Yu Hongtao, a domestic scholar, pointed out that it is necessary to organize the training of different content according to the different stages of the reform of blending teaching mode [5]. Teachers clearly distinguish blending teaching from the traditional and conventional teaching classes, and make blending teaching class a special classroom with personal experience, self-understanding, conscientious and natural cognition of society to build a practical base for cultivating students'innovative ability in colleges and universities. The aim of blending teaching model is not only improving the achievement of a certain subject, but also improving the overall quality of students and achieving the ultimate goal of cultivating socialist successors.

\section{Acknowledgement}

This research was financially supported by Educational Science Planning Subject in Shaanxi Province, "Research on MOOC, microlecture and flipped classroom and blending teaching mode in application-oriented universities"(Project number: SGH17H402)

\section{References}

[1] Yang Zhichao. Analysis of construction path of blending teaching mode of ideological and political theory course in colleges and universities, Ideological Education Research, vol.6, pp. 69,2016 .

[2] Zhang Qiliang, Wang AIchun, Research on a new blending teaching mode based on flipped classroom ,Modern educational technology, vol.6, pp. 28,2014.

[3] Wei Shoulian. Construction and application of blending teaching mode ,Journal of Zhaoqing University, vol.3,pp. 57,2014.

[4] Gao Jianhua. Research on blending teaching mode of ideological and political course based on MOOC platform ,Modern Educational Science, vol.1, pp. 34,2015.

[5] Yu Hongtao. Case study of promoting blending teaching mode reform in colleges and universities through training__nner Mongolia University For The Nationlities, Modern Educational Science, vol.10,pp. 77,2017. 